${ }^{1}$ Department of Cardiology and Internal Medicine, Collegium Medicum, Nicolaus Copernicus University, Bydgoszcz, Poland

2National Heart \& Lung Institute, Imperial College, London, United Kingdom

${ }^{3}$ Postgraduate Medical School, University of Hertfordshire, Hertfordshire, United Kingdom

${ }^{4}$ Department of Cardiology, East and North Hertfordshire NHS Trust, Hertfordshire, United Kingdom

\title{
Does morphine remain a standard of care in acute myocardial infarction?
}

\author{
Corresponding author: \\ Małgorzata Ostrowska \\ Department of Cardiology \\ and Internal Medicine, \\ Collegium Medicum, \\ Nicolaus Copernicus University, \\ 9 Skłodowskiej-Curie Street, \\ 85-094 Bydgoszcz, Poland \\ e-mail:m.ostrowska@cm.umk.p \\ Medical Research Journal 2020; \\ Volume 5, Number 1, 46-49 \\ 10.5603/MRJ.a2020.0009 \\ Copyright $(2020$ Via Medica \\ ISSN 2451-2591
}

\begin{abstract}
Morphine is routinely used for pain relief in patients with acute myocardial infarction. However, it was documented that morphine decreases the bioavailability and antiplatelet effect of $\mathrm{P}_{2} \mathrm{Y}_{12}$ receptor inhibitors. Multiple strategies to overcome this undesirable interaction are currently under investigation; they include the following: administration of crushed ticagrelor tablets, co-administration of metoclopramide, bridging with intravenous antiplatelet agents, or replacement of morphine with other analgesic. Adequately powered randomised trials examining the clinical consequences of concomitant use of morphine and $\mathrm{P}_{2} \mathrm{Y}_{12}$ receptor inhibitors are still lacking.

Key words: morphine, $\mathrm{P} \mathrm{Y}_{12}$ receptor inhibitors, clopidogrel, ticagrelor, prasugrel, myocardial infarction
\end{abstract}

Med Res J 2020; 5 (1): 46-49

\section{Introduction}

Alleviation of chest pain is of paramount importance in the treatment of patients with acute myocardial infarction (MI). Titrated intravenous morphine is the most widely used method in this clinical setting [1]. The choice of such powerful analgesics as opioids is motivated by the necessity of providing comfort, but also to attenuate sympathetic activation, which leads to vasoconstriction and increased afterload of the heart. According to the current European Society of Cardiology (ESC) guidelines on acute myocardial infarction in patients presenting with ST-segment elevation (STEMI), titrated intravenous opioids should be considered to relieve pain (class of recommendation Ila, level of evidence C) [2]. It is noteworthy that, as compared to previous guidelines, the class of recommendation for morphine use in STEMI has been lowered from I to Ila (i.e. from "it is indicated" to "it should be considered") with the same level of evidence $C$ (i.e. consensus of opinion of the experts) due to the unfavourable impact of morphine on $\mathrm{P}_{2} \mathrm{Y}_{12}$ inhibitors bioavailability and antiplatelet effect [2-4].

\section{Interaction between morphine and antiplatelet agents}

Dual antiplatelet therapy composed of aspirin and a P2Y ${ }_{12}$ receptor inhibitor is a cornerstone of treatment in patients with acute coronary syndromes (ACS) [4, 5]. In modern ACS therapy the ESC guidelines clearly recommend the use of more potent antiplatelet agents like ticagrelor and prasugrel over clopidogrel [6]. In a double-blind cross-over trial in healthy volunteers, morphine had no significant effect on aspirin-induced platelet inhibition [7]. The first reports suggesting possible drug-drug interaction between morphine and clopidogrel come from the CRUSADE registry [8]. In this registry the incidence of the composite endpoint of death and myocardial infarction was significantly higher in patients who received intravenous morphine as compared with those who did not. In a randomised, placebo-controlled, pharmacokinetic trial in healthy volunteers the administration of morphine was associated with delayed and reduced maximal plasma concentration of ticagrelor [9]. In the first hours of treatment in STEMI, as compared with non-ST-segment elevation 
myocardial infarction (NSTEMI), ticagrelor concentrations as well as its antiplatelet effect was found to be reduced in the prospective, observational PINPOINT trial [10]. It was further documented that independent predictors of high on-treatment platelet reactivity within the initial hours of antiplatelet treatment with ticagrelor in ACS patients are the presence of STEMI and morphine co-administration [11]. The first randomised study demonstrating the unfavourable interaction between morphine and ticagrelor in the acute Ml setting was the double-blind, placebo-controlled, pharmacokinetic-pharmacodynamic IMPRESSION trial [4]. The study provided evidence that morphine decreases not only the bioavailability, but also the antiplatelet effect of ticagrelor in patients with MI. Similar observations of delayed onset of action with concomitant use of morphine were also reported for prasugrel $[12,13]$.

\section{The mechanism of interaction between morphine and $\mathrm{P2Y}_{12}$ receptor inhibitors}

Morphine frequently induces nausea and vomiting [14]. Moreover, the stimulation of opioid receptors in the myenteric plexus and the intestines is responsible for reduction of intestinal motility and production of intestinal secretes [15]. Additionally, increased sympathetic activation and selective perfusion of vital organs results in delayed stomach emptying, slower intestinal transit, and deferred drug absorption. Interestingly, impaired gastrointestinal absorption is probably also responsible for the delayed antiplatelet effect of potent $\mathrm{P}_{2} \mathrm{Y}_{12}$ inhibitors observed within the first hours of treatment in $\mathrm{Ml}$ patients managed with mild therapeutic hypothermia, as well as in critically ill patients $[16,17]$.

\section{Therapeutic strategies to overcome the interaction between morphine and P2Y 12 receptor inhibitors}

Several options have been proposed in the literature to either avoid or diminish the undesirable interaction between morphine and $\mathrm{P}_{2} \mathrm{Y}_{12}$ receptor inhibitors. First, administration of crushed ticagrelor tablets as compared with the integral ones was associated with shorter time to reach maximum plasma concentration of ticagrelor and lower platelet reactivity at one hour post loading dose in STEMI patients [18]. It is worth mentioning that sublingual administration of crushed ticagrelor tablets was related to slower absorption and higher platelet reactivity within the first hour following ticagrelor loading dose, compared with crushed tablets administered orally in patients with unstable angina [19]. Second, the co-administration of a prokinetic agent - metoclopramide - was associated with higher ticagrelor concentration and lower platelet reactivity within the first hour post ticagrelor loading dose in patients with unstable angina [20]. Third, the idea of intravenous co-administration of a peripheral opioid antagonist - methylnaltrexone - showed only marginal differences in ticagrelor concentration and no effect on platelet reactivity [21]. Fourth, the co-administration of a glycoprotein IIb/IIla receptor antagonist — abciximab — provided prompt and efficient platelet inhibition in prasugrel-treated STEMI patients receiving morphine [13]. Fifth, although it has not been examined yet, the co-administration of an intravenous direct-acting $\mathrm{P}_{2 \mathrm{Y}_{12}}$ receptor antagonist - cangrelor — might also be a possible solution [22]. And, sixth, the last proposed strategy to overcome the negative impact of morphine may be a replacement of morphine with another powerful, short-acting opioid analgesic like alfentanil [23].

\section{Clinical consequences of interaction between morphine and $\mathrm{P}_{2} \mathrm{Y}_{12}$ receptor inhibitors}

Morphine co-administration in ticagrelor-treated patients with ACS is a strong predictor of high on-treatment platelet reactivity within the first hours after ticagrelor loading dose, when a sufficient antiplatelet effect is particularly desired [11]. High on-treatment platelet reactivity is a significant and well-documented risk factor of atherothrombotic events [24-26]. It has been postulated that delayed onset of antiplatelet action in MI patients receiving morphine may translate into increased risk of adverse cardiovascular events $[4,9$, 27-29]. However, to date, we lack adequately powered randomised studies investigating this hypothesis. Additionally, morphine use in STEMI patients is not only associated with increased platelet reactivity, but also reduced spontaneous myocardial reperfusion and larger infarct size [30]. In a recently published meta-analysis including one randomised trial and 10 observational studies, periprocedural intravenous morphine use in STEMI patients treated with an oral $\mathrm{P}_{2} \mathrm{Y}_{12}$ receptor inhibitor (ticagrelor $59.7 \%$, clopidogrel $33.5 \%$, and prasugrel $6.8 \%$ ) and undergoing $\mathrm{PCl}$ was not associated with adverse short-term clinical outcomes [31]. Yet, the included randomised trial comprised only 35 morphine-treated subjects, and there was only one reported adverse event [4]. Further randomised trials exploring the effect of morphine use on clinical outcomes in MI patients are greatly needed. 


\section{Conclusions}

I. Morphine decreases bioavailability and antiplatelet effect of $\mathrm{P}_{2} \mathrm{Y}_{12}$ receptor inhibitors in patients with acute MI.

II. Therapeutic strategies to overcome the interaction between morphine and $\mathrm{P}_{2} \mathrm{Y}_{12}$ receptor inhibitors include: administration of crushed ticagrelor tablets, co-administration of metoclopramide, bridging with abciximab or cangrelor, or replacement of morphine with short-acting alfentanil.

III. Adequately powered randomised studies exploring the influence of concomitant use of morphine and $\mathrm{P}_{2 \mathrm{Y}_{12}}$ receptor inhibitors on clinical outcomes are lacking.

IV. Morphine remains a standard of care in acute Ml; however, it should be co-administered with antiplatelet agents after careful evaluation of the clinical situation.

\section{References}

1. Kubica J, Adamski P, Paciorek P, et al. Treatment of patients with acute coronary syndrome: Recommendations for medical emergency teams Focus on antiplatelet therapies. Updated experts' standpoint. Cardio J. 2018; 25(3): 291-300, doi: 10.5603/CJ.a2018.0042, indexed in Pubmed: 29671864.

2. Ibanez B, James S, Agewall S, et al. ESC Scientific Document Group. 2017 ESC Guidelines for the management of acute myocardial infarction in patients presenting with ST-segment elevation: The Task Force for the management of acute myocardial infarction in patients presenting with ST-segment elevation of the European Society of Cardiology (ESC). Eur Heart J. 2018; 39(2): 119-177, doi: 10.1093/eurhearti/ehx393, indexed in Pubmed: 28886621.

3. Steg PhG, James SK, Atar D, et al. Task Force on the management of ST-segment elevation acute myocardial infarction of the European Society of Cardiology (ESC). ESC Guidelines for the management of acute myocardial infarction in patients presenting with ST-segment elevation. Eur Heart J. 2012; 33(20): 2569-2619, doi: 10.1093/eurheartj/ehs215 indexed in Pubmed: 22922416.

4. Kubica J, Adamski P, Ostrowska M, et al. Influence of Morphine on Pharmacokinetics and Pharmacodynamics of Ticagrelor in Patients with Acute Myocardial Infarction (IMPRESSION): study protocol for a randomized controlled trial. Trials. 2015; 16(3): 198-252, doi 10.1186/s13063-015-0724-z, indexed in Pubmed: 25925591.

5. Roffi M, Patrono C, Collet JP, et al. ESC Scientific Document Group 2015 ESC Guidelines for the management of acute coronary syndromes in patients presenting without persistent ST-segment elevation: Task Force for the Management of Acute Coronary Syndromes in Patients Presenting without Persistent ST-Segment Elevation of the European Society of Cardiology (ESC). Eur Heart J. 2016; 37(3): 267-315, doi: 10.1093/eurheartj/ehv320, indexed in Pubmed: 26320110.

6. Neumann FJ, Sousa-Uva M, Ahlsson A, et al. ESC Scientific Document Group, ESC Scientific Document Group . Considerations for the choice between coronary artery bypass grafting and percutaneous coronary intervention as revascularization strategies in major categories of patients with stable multivessel coronary artery disease: an accompanying article of the task force of the 2018 ESC/EACTS guidelines on myocardial revascularization. Eur Heart J. 2019; 40(2): 204-212, doi 10.1093/eurhearti/ehy532, indexed in Pubmed: 30165435.

7. Bartko J, Schoergenhofer C, Schwameis M, et al. Morphine Interaction with Aspirin: a Double-Blind, Crossover Trial in Healthy Volunteers. J Pharmacol Exp Ther. 2018; 365(2): 430-436, doi: 10.1124/jpet.117.247213, indexed in Pubmed: 29540563.

8. Meine TJ, Roe MT, Chen AY, et al. CRUSADE Investigators. Association of intravenous morphine use and outcomes in acute coronary syndromes: results from the CRUSADE Quality Improvement Initiative. Am Heart J. 2005; 149(6): 1043-1049, doi: 10.1016/j.ahj.2005.02.010, indexed in Pubmed: 15976786.
9. Hobl EL, Reiter B, Schoergenhofer C, et al. Morphine decreases ticagrelor concentrations but not its antiplatelet effects: a randomized trial in healthy volunteers. Eur J Clin Invest. 2016; 46(1): 7-14, doi: 10.1111/eci.12550, indexed in Pubmed: 26449338.

10. Adamski P, Sikora J, Laskowska E, et al. Comparison of bioavailability and antiplatelet action of ticagrelor in patients with ST-elevation myocardial infarction and non-ST-elevation myocardial infarction: A prospective, observational, single-centre study. PLoS One. 2017; 12(10): e0186013, doi: 10.1371/journal.pone.0186013, indexed in Pubmed: 29023473

11. Adamski P, Buszko K, Sikora J, et al. Determinants of high platelet reactivity in patients with acute coronary syndromes treated with ticagrelor. Sci Rep. 2019; 9(1): 3924, doi: 10.1038/s41598-019-40628-0, indexed in Pubmed: 30850677.

12. Thomas MR, Morton AC, Hossain R, et al. Morphine delays the onset of action of prasugrel in patients with prior history of ST-elevation myocardial infarction. Thromb Haemost. 2016; 116(1): 96-102, doi: 10.1160/TH16-02-0102, indexed in Pubmed: 27099137.

13. Siller-Matula JM, Specht S, Kubica J, et al. Abciximab as a bridging strategy to overcome morphine-prasugrel interaction in STEMI patients. Br J Clin Pharmacol. 2016; 82(5): 1343-1350, doi: 10.1111/bcp.13053, indexed in Pubmed: 27366874

14. Parodi G. Editor's Choice-Chest pain relief in patients with acute myocardial infarction. Eur Heart J Acute Cardiovasc Care. 2016; 5(3): 277-281, doi: 10.1177/2048872615584078, indexed in Pubmed: 25904757.

15. Holzer P. Opioid receptors in the gastrointestinal tract. Regul Pept. 2009; 155(1-3): 11-17, doi: 10.1016/i.regpep.2009.03.012, indexed in Pubmed: 19345246.

16. Umińska JM, Ratajczak J, Buszko K, et al. Impact of mild therapeutic hypothermia on bioavailability of ticagrelor in patients with acute myocardial infarction after out-of-hospital cardiac arrest. Cardiol J. 2019 [Epub ahead of print], doi: 10.5603/CJ.a2019.0024, indexed in Pubmed: 30799546.

17. Schoergenhofer $\mathrm{C}$, Hobl EL, Staudinger T, et al. Prasugrel in critically ill patients. Thromb Haemost. 2017; 117(8): 1582-1587, doi: 10.1160/TH17-03-0154, indexed in Pubmed: 28692105.

18. Alexopoulos D, Barampoutis N, Gkizas V, et al. Crushed Versus Integral Tablets of Ticagrelor in ST-Segment Elevation Myocardial Infarction Patients: A Randomized Pharmacokinetic/Pharmacodynamic Study. Clin Pharmacokinet. 2016; 55(3): 359-367, doi: 10.1007/s40262-0150320-0, indexed in Pubmed: 26315810.

19. Niezgoda P, Sikora J, Barańska M, et al. Crushed sublingual versus oral ticagrelor administration strategies in patients with unstable angina. A pharmacokinetic/pharmacodynamic study. Thromb Haemost. 2017; 117(4): 718-726, doi: 10.1160/TH16-08-0670, indexed in Pubmed: 28203684

20. Sikora J, Niezgoda P, Barańska M, et al. METoclopramide Administration as a Strategy to Overcome MORPHine-ticagrelOr Interaction in PatientS with Unstable Angina PectorlS-The METAMORPHOSIS Trial. Thromb Haemost. 2018; 118(12): 2126-2133, doi: 10.1055/s-00381675605, indexed in Pubmed: 30453344.

21. Franchi F, Rollini F, Park Y, et al. Effects of Methylnaltrexone on Ticagrelor-Induced Antiplatelet Effects in Coronary Artery Disease Patients Treated With Morphine. JACC Cardiovasc Interv. 2019; 12(16): 15381549, doi: $10.1016 /$ i.jcin.2019.05.028, indexed in Pubmed: $\underline{31377269}$.

22. Kubica J, Kozinski M, Navarese EP, et al. Cangrelor: an emerging therapeutic option for patients with coronary artery disease. Curr Med Res Opin. 2014; 30(5): 813-828, doi: 10.1185/03007995.2014.880050, indexed in Pubmed: 24393016.

23. Kubica J, Kubica A, Jilma B, et al. Impact of morphine on antiplatelet effects of oral P2Y12 receptor inhibitors. Int J Cardiol. 2016; 215: 201208, doi: 10.1016/i.ijcard.2016.04.077, indexed in Pubmed: 27128531.

24. Aradi D, Komócsi A, Vorobcsuk A, et al. Prognostic significance of high on-clopidogrel platelet reactivity after percutaneous coronary intervention: systematic review and meta-analysis. Am Heart J. 2010; 160(3): 543-551, doi: 10.1016/j.ahj.2010.06.004, indexed in Pubmed: 20826265

25. Stone GW, Witzenbichler B, Weisz G, et al. ADAPT-DES Investigators. Platelet reactivity and clinical outcomes after coronary artery implantation of drug-eluting stents (ADAPT-DES): a prospective multicentre registry study. Lancet. 2013; 382(9892): 614-623, doi: 10.1016/S0140-6736(13)61170-8, indexed in Pubmed: 23890998.

26. Ostrowska M, Kubica J, Adamski $P$, et al. Stratified Approaches to Antiplatelet Therapies Based on Platelet Reactivity Testing. Front Cardiovasc Med. 2019; 6: 176, doi: 10.3389/fcvm.2019.00176, indexed in Pubmed: 31850373

27. Hobl EL, Stimpfl T, Ebner J, et al. Morphine decreases clopidogrel concentrations and effects: a randomized, double-blind, placebo-con- 
trolled trial. J Am Coll Cardiol. 2014; 63(7): 630-635, doi: 10.1016/i. jacc.2013.10.068, indexed in Pubmed: 24315907.

28. Hobl EL, Reiter B, Schoergenhofer C, et al. Morphine interaction with prasugrel: a double-blind, cross-over trial in healthy volunteers. Clin Res Cardiol. 2016; 105(4): 349-355, doi: 10.1007/s00392-015-0927-Z. indexed in Pubmed: 26493304.

29. Parodi G, Bellandi B, Xanthopoulou I, et al. Morphine is associated with a delayed activity of oral antiplatelet agents in patients with ST-elevation acute myocardial infarction undergoing primary percutaneous coronary intervention. Circ Cardiovasc Interv. 2015; 8(1), doi: 10.1161/CIRCINTERVENTIONS.114.001593, indexed in Pubmed: 25552565.
30. Farag M, Spinthakis N, Srinivasan M, et al. Morphine Analgesia Pre-PPCl Is Associated with Prothrombotic State, Reduced Spontaneous Reperfusion and Greater Infarct Size. Thromb Haemost. 2018 118(3): 601-612, doi: 10.1055/s-0038-1629896, indexed in Pubmed: $\underline{29444530}$

31. Batchelor R, Liu DH, Bloom J, et al. Association of periprocedural intravenous morphine use on clinical outcomes in ST-elevation myocardial infarction (STEMI) treated by primary percutaneous coronary intervention: Systematic review and meta-analysis. Catheter Cardiovasc Interv. 2019 [Epub ahead of print], doi: 10.1002/ccd.28561, indexed in Pubmed: 31654491. 